ISSN 2075-163X

www.mdpi.com/journal/minerals/

Article

\title{
Initial Assemblage of Bacterial Saccharic Fibrils and Element Deposition to Form an Immature Sheath in Cultured Leptothrix sp. Strain OUMS1
}

\author{
Mitsuaki Furutani, Tomoko Suzuki, Hiromichi Ishihara, Hideki Hashimoto, Hitoshi Kunoh and \\ Jun Takada *
}

Department of Material Chemistry, Graduate School of Natural Science and Technology, Okayama University, 3-1-1 Tsushima-naka, Kita-ku, Okayama 700-8530, Japan;

E-Mails: dns421306@s.okayama-u.ac.jp (M.F.); suzukito@cc.okayama-u.ac.jp (T.S.);

hishihara@cc.okayama-u.ac.jp (H.I.); hideki-h@cc.okayama-u.ac.jp (H.H.);

hkunoh@cc.okayama-u.ac.jp (H.K.)

* Author to whom correspondence should be addressed; E-Mail: jtakada@cc.okayama-u.ac.jp; Tel.: +81-86-251-8107; Fax: +81-86-251-8087.

Received: 9 November 2011; in revised form: 30 November 2011 / Accepted: 8 December 2011 / Published: 14 December 2011

\begin{abstract}
In an aquatic environment, the genus Leptothrix produces an extracellular Fe- or Mn-encrusted tubular sheath composed of a complex hybrid of bacterial exopolymers and aqueous-phase inorganic elements. This ultrastructural study investigated initial assemblage of bacterial saccharic fibrils and subsequent deposition of aqueous-phase inorganic elements to form the immature sheath skeleton of cultured Leptothrix sp. strain OUMS1. After one day of culture, a globular and/or thread-like secretion was observed on the surface of the bacterial cell envelope, and secreted bodies were transported across the intervening space away from the cell to form an immature sheath skeleton comprising assembled and intermingled fibrils. Energy dispersive X-ray microanalysis and specific Bi-staining detected a distinguishable level of $\mathrm{P}$, trace $\mathrm{Si}$, and a notable amount of carbohydrates in the skeleton, but not Fe. By the second day, the skeleton was prominently thickened with an inner layer of almost parallel aligned fibrils, along with low level of Fe deposition, whereas an outer intermingled fibrous layer exhibited heavy deposition of $\mathrm{Fe}$ along with significant deposition of $\mathrm{P}$ and Si. These results indicate that basic sheath-construction proceeds in two steps under culture conditions: an initial assemblage of
\end{abstract}


bacterial saccharic fibrils originated from the cell envelope and the subsequent deposition of aqueous-phase $\mathrm{Fe}, \mathrm{P}$, and $\mathrm{Si}$.

Keywords: Leptothrix; iron-oxidizing bacterium; inorganic/organic complex; bacterial saccharic fibril; initial formation of Leptothrix sheath

\section{Introduction}

The genus Leptothrix is a type of Fe/Mn-oxidizing bacteria that belongs to the aquatic $\beta$-proteobacteria [1-3]. Leptothrix spp. are characterized by the formation of an extracellular, tubular, Fe- or Mn-encrusted sheath, which is closely associated with the Fe-accumulating and Mn-oxidizing capacities of this genus. Many earlier reports have shown that the Leptothrix sheath matrix is a complex hybrid of bacterial exopolymers and aqueous-phase inorganic elements [2,4-7]. Ghiorse [6] noted that the sheath of Leptothrix comprises a metal-impregnated organic matrix that may be synthesized and excreted from the surface of the bacterial cell envelope. Recently, Suzuki et al. [8,9] demonstrated using electron energy-loss spectroscopy that both sheath- and stalk-fibers of L. ochracea and Gallionella ferruginea, respectively, have a carbon core of bacterial exopolymers and that aqueous-phase iron interacts with oxygen at the surface of the carbon core, resulting in the deposition of iron oxides at the surface. These reports support the hypothesis presented by Chan et al. [10] that organic polymers play important roles in ecosystems by accumulating biologically important elements and that microbial polymers could scavenge iron oxide particles and induce the crystallization of unexpected phases. Despite the growing body of evidence and this hypothesis related to the structural and spatial associations found in this organic/inorganic hybrid, little is known regarding how and when the construction of such a hybrid might be initiated. An understanding of the initial phase of hybrid construction would provide a better insight into this remarkable bacterium-associated phenomenon.

This biologically derived organic/inorganic hybrid is chemically and physically active and thus is considered as a future-oriented promising functional material. Our group termed this bacterium-associated Fe-rich hybrid "biogenous iron oxide (BIOX)" and has concentrated on characterizing it [8,9,11-14] and on challenging its practical uses as a BIOX-immobilized palladium catalyst for the solvent-free Suzuki-Miyaura coupling reaction [15], an immobilization supporter for enzymatic function [16], and a unique pigment for ceramics.

In a previous paper [11], we reported the use of various microscopic techniques to visualize the assemblage of bacterial saccharic fibrils during the formation of a fibrous layer, and the subsequent deposition of aqueous-phase inorganic elements on the layer contributed to the production of the initial sheath skeleton of cultured Leptothrix sp. strain OUMS1 [12]. This previous study highlighted the significance of bacterial secretion during the initial phase of sheath formation, but failed to provide any insight into how and when aqueous-phase inorganic elements are impregnated into the sheath skeleton. In the present study, we cultured OUMS1 and observed the time course of inorganic deposition in the immature sheath skeleton by transmission electron microscopy (TEM), scanning transmission electron microscopy (STEM), high-angle annular dark-field scanning transmission electron microscopy (HAADF-STEM), and energy dispersive X-ray (EDX) spectroscopy. 


\section{Results and Discussion}

Details of the initial phase of assemblage of bacterial saccharic fibrils in the OUMS1 sheath skeleton during days 1-3 of culture were shown using various light and electron microscopic techniques [11]. Further insights into the initial phase of sheath formation were provided by this study. TEM images of $\mathrm{U} / \mathrm{Pb}$-stained sections showed that secretion occurred from the entire cell envelope of bacterial cells to form non-membrane-bound long threads with a swollen tip (Figure 1(a), inset) and round to oblong globules, within 1 day of culture (Figure 1(a), white arrows). Furutani et al. [11] used cytochemical techniques to demonstrate that these globules were rich in saccharic materials. Notably, the apex of some threads was evaginated to form a tiny oblong globule measuring 50-100 nm in length and $30-40 \mathrm{~nm}$ in diameter (Figure 1(a,b), white arrows), which resembled globules attached to the immature sheath in size and shape (Figure 1(b), dotted arrow). The STEM image of a U/Pb-stained section (Figure 1(a), inset) revealed threads, where one was connected to the cell envelope and another was disconnected at its base, and the apical globules of these threads had a relatively high electron density, suggesting that these structures could be rich in saccharic polymers. Ghiorse [6] obtained thin sections of Leptothrix from natural samples and stained them with ruthenium red (RR) after acidified leukoberbelin blue-extraction, and identified threads of RR-stained acidic polymers that made contact with projecting areas of the cell envelope. Based on this finding it was inferred that the Leptothrix sheath was composed of a metal-impregnated organic matrix that might have been synthesized and excreted at contact points along the surface of the bacterial cell envelope. The non-membrane-bound globules and/or threads identified in the present study probably corresponded to the RR-stained threads, although no evidence of metal deposition was obtained at this stage. After being released from the cell envelope, these globules (Figure 1(b), dotted arrow) moved outwards and assembled to form an immature fibrous sheath layer (Figure 1(b), IS) away from the cell, leading to the production of an intervening space between the cell and the sheath layer (Figure 1(b), IVS). In general, extracellular polymers from microbial cells are believed to facilitate microbe-colloid attachment and aggregation of biogenic particles on cell surfaces when biofilms are formed in aquatic environments [17,18]. Nevertheless, Leptothrix sheaths always form across the bacterial cells and the intervening space is a particularly notable feature in aged sheaths $[4,6,11,12,19]$. One possibility that the space resulted from the contraction in cell volume during the pretreatment for electron microscopy (fixing, drying, staining, etc.) can not be ruled out. However, as illustrated in Supplementary Figure S1, this space is clearly distinguishable in living materials by phase-contrast and differential interference contrast microscopy and viable/dead staining [11]. Therefore, we consider that this space is not attributable to artifact during specimen preparation. Furutani et al. [11] inferred that this space, probably a liquid phase, could play a significant role in the continuous transfer of bacterial saccharic polymers and other secretion products from the cell to the sheath layer. However, the significance of this space for sheath formation remains uncertain.

Continuous globule- and/or thread-type secretions and their transfer to the immature sheath skeleton contributed to the thickening of the layer in which aqueous-phase inorganic elements began to deposit, resulting in the high electron density of the fibrous components found in the layer by the second day of culture (Figure 1(c), IS). The assembled fibrils may have been arrayed almost parallel to the inner surface of the immature sheath during sheath maturation (Figure 1(c,d), single star), whereas the outer 
electron-dense fibrils (Figure 1(c,d), double star) were notably fluffy and intermingled, thereby resulting in varying thickness throughout the sheath area (Figure 1(c), IS). This phase may be a turning point in the partitioning of the inner and outer layers, which are is commonly observed in aged sheaths [4,11-13].

Figure 1. TEM and STEM images of OUMS1 and associated structures in U/Pb-stained cross sections. (a) Bacterial cell surrounded by a cell envelope in a one-day-old culture. The immature sheath layer has not yet formed. White arrows: globular projections from the surface of the cell envelope. Inset (STEM image): thread-type projections measuring ca. 300-400 nm in length with a swollen tip; (b) A cell and an immature sheath skeleton formed away from the cell, leaving an intervening space (one-day-old culture); (c) A cell and associated immature sheath with an inner layer fibril assembly (single star) and an outer layer composed of highly electron dense fibril assembly (double star); (d) Enlarged image of a cross section of a bacterial cell in (c). Note that fibrils in the inner layer (single star) are almost aligned in parallel, while those in the outer layer (double star) are fluffy and extremely electron dense, suggesting heavy deposition of aqueous-phase inorganic elements. Scale bars $=200 \mathrm{~nm}$. BC, bacterial cell; CE, cell envelope; IS, immature sheath; IVS, intervening space.

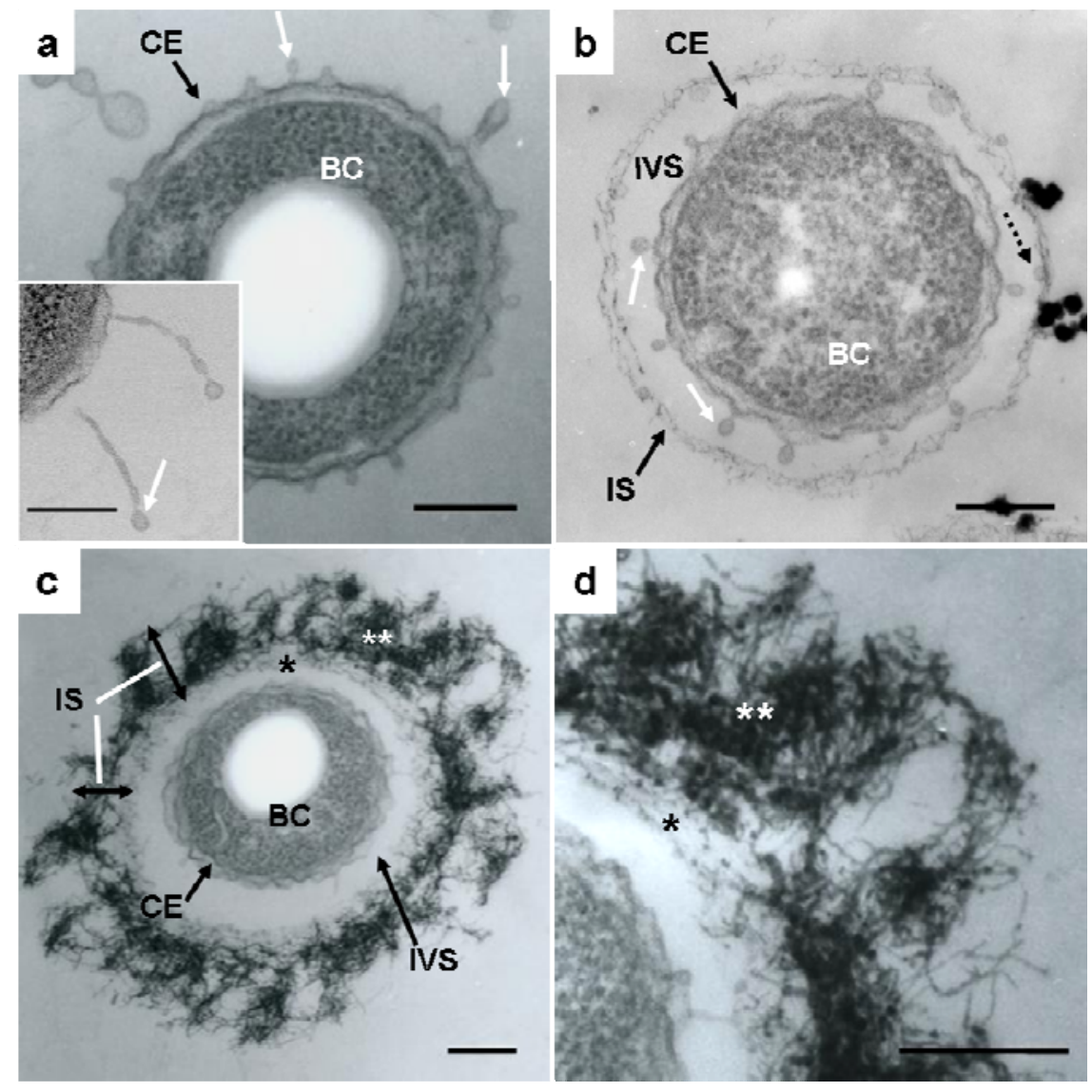

Detailed observations of HAADF-STEM images and EDX analyses were performed on Bi-stained sections prepared from day 1 and 2 cultures, with a focus on the daily changes in fine structures and elemental detection. Within one day an immature sheath layer had formed across the bacterial cell (Figure 2(a)). The immature layer (Figure 2(a), IS) was approximately $100 \mathrm{~nm}$ thick and it appeared to 
comprise a randomly networked assembly of fine fibrils. This layer was visible in HAADF-STEM images, but barely visible by light microscopy because of its low thickness and poor contrast. Single globules and threads secreted from the cell envelope were often observed in isolation in the intervening space between the cell and sheath. As was expected, Bi staining revealed that the immature sheath contained the saccharic materials as similarly as the bacterial cell (Figure 2(b)). Distinguishable signals for P were detected in the cell and associated structures (Figure 2(d)). P is an essential element in cells and the assembled fibrils are of cellular origin [11], so its distribution over these structures was expected. Weak signals of Si were detected also in the intervening space and the structure-unrelated background besides the cell and associated structures (Figure 2(e)). Because Si is a ubiquitous element in environments, its trace level is generally detected everywhere. Significant Fe signals were not detected at this stage in any related structures (Figure 2(c)), which indicated negligible deposition of aqueous-phase Fe in the sheath area at this stage. Judging from the only distinguishable distribution of $\mathrm{P}$ and $\mathrm{Si}$ in both the cell and immature sheath, environmental P and Si were not strongly deposited on the sheath fibrils within one day of culture.

Figure 2. HAADF-STEM images of OUMS1 and associated structures in Bi-stained cross sections prepared from a one-day-old culture and elemental maps by EDX area analysis. (a) Enlarged image of a cross section of a bacterial cell with the immature sheath shown in inset. Note the apparent fibril features of the immature sheath; (b) Bi distribution map showing intense signals in both the cell and immature sheath; (c) Fe distribution map showing no remarkable signals; (d) P distribution map showing a similar distribution pattern as that with $\mathrm{Bi}$; (e) Si distribution map showing weak signals in all structures, even in the intervening space. Scale bar $=100 \mathrm{~nm}$, except $500 \mathrm{~nm}$ in (a) inset. BC, bacterial cell; $\mathrm{CE}$, cell envelope; IS, immature sheath; IVS, intervening space.
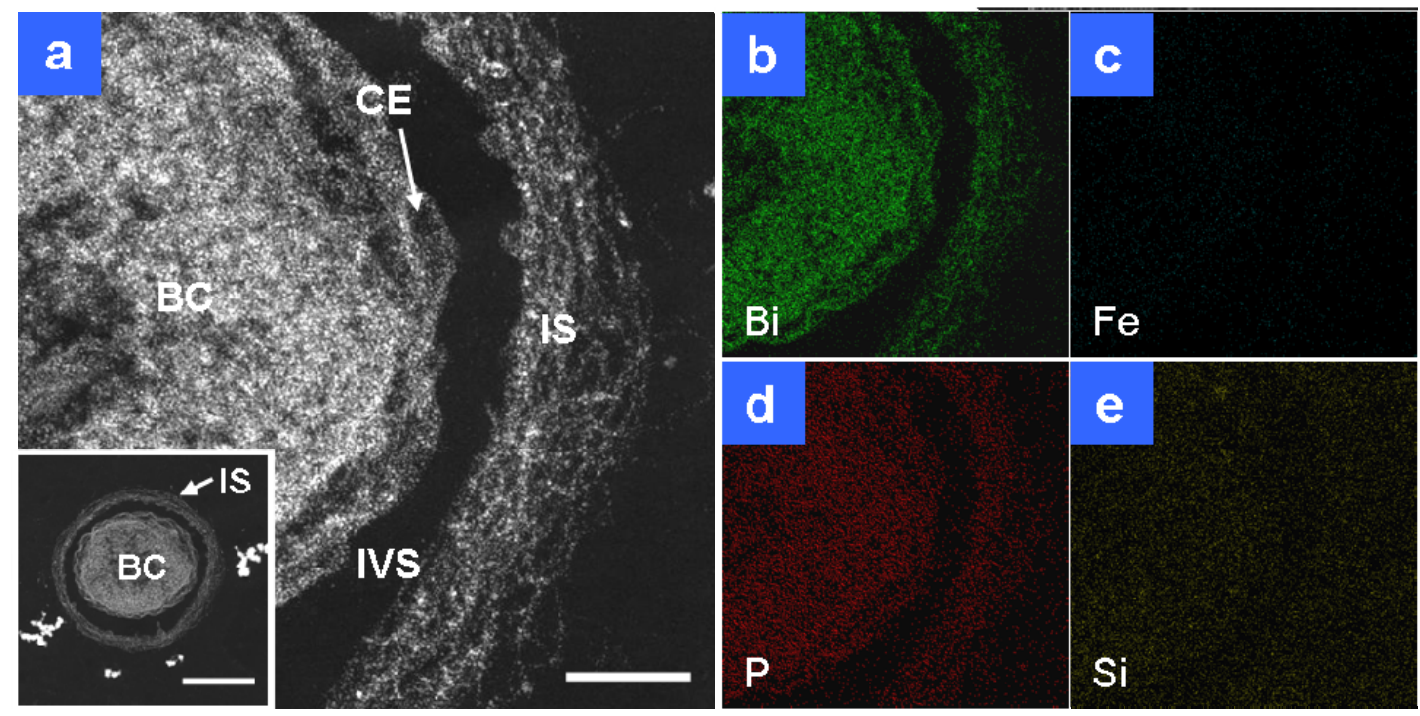

After two days of culture, the sheath area (Figure 3(a), IS) and its fibrils, particularly the outer intermingled fibrils, showed an increase in electron density, and the width of the area reached 120-200 nm. Compared with the sheath fibrils in Figure 2(a), those in Figure 3(a) (single star) were much thicker, which probably reflected further accumulation of saccharic polymers and/or heavier 
deposition of aqueous-phase inorganic elements between days 1 and 2. Bi staining detected extremely stronger signals on the entire sheath area than in the cell (Figure 3(b)), which indicated substantial assemblage of saccharic polymers in the sheath area. In theory, the contrast of HAADF-STEM images depends on the square of the atomic number [8], which means that a high electron density is at least partially attributable to the presence of considerable amounts of heavy elements as well as Bi-responding carbohydrates. P and Si were similarly distributed over all sheath fibrils (Figure 3(d,e)), reflecting their ubiquitous presence in the cells and the surrounding environment. The stronger signal intensity of both elements in the sheath area compared with the cell might plausibly reflect their external deposition from the aquatic environment. Figure 1(c) shows that the sheath fibrils located at and near their outer surface (Figure 1(c), double star) had a higher contrast than those near the intervening space (Figure 1(c), single star). Figure 3 shows that extremely intense Fe signals were detected in the intermingled fibrils at the sheath surface area (Figure 3(c), double star) and that P and Si signals were detected at the same site (Figure 3(d,e), double star). Thus, regardless of the presence of considerable amounts of saccharic polymers at the inner sheath site (Figure 3(b), single star), the Fe, P, and Si signals (Figure 3(c-e), single star) were lower at the same site when compared with the outer intermingled fibril site. Whether these images reflect the variable thickness of fibrous layers or variable degrees of deposition of aqueous-phase inorganic elements at both sites remain uncertain. The images reflect the initial deposition of aqueous-phase inorganic elements, particularly Fe, on the outer intermingled fibrils, followed by subsequent inward deposition.

Spring [1] noted that Fe impregnation and covering of Leptothrix sheaths probably occurred after cells had left their envelopes, but these phenomena may have occurred on the immature sheath of cells under culture conditions before cellular release. In summary, these observations indicated that the basic construction of the sheath proceeds in two steps under culture conditions: assemblage of saccharic fibrils of bacterial origin [11] through globular and/or thread-like structures projecting from the cell envelope, followed by deposition of aqueous-phase Fe, P, and Si. However, because the deposition of aqueous-phase elements seems to await the completion of initial assemblage of fibrils secreted from cells, one possibility can not be ruled out that the element deposition may occur even in the first stage with undetectable trace densities of initial sheath and elements.

Various bacteria possess long filamentous structures known as pili or fimbriae that extend from their cell surface. It is well known that these filamentous structures are involved in the secretion of various proteins and/or nucleic acids, and they play significant roles in attachment, pathogenicity, biofilm formation, and other functions [20-22]. The pili of Gram-negative bacteria have variable shapes and sizes, but they are several micrometers in length and 2-8 $\mathrm{nm}$ in width [22]. The thread-type structures identified in the present study project from the cell envelope, but they are not comparable to known pili in shape and size. Thus, we inferred that these thread-type structures may be involved in the transportation of secreted saccharic polymers under a similar mechanism to that found in pili. We hypothesized that the intervening space between the cell and the sheath could be determined by the distance of saccharic polymer transportation. Whether the thread-type structures represent a major structure involved in transportation or if they are pili/fimbriae-type structures formed from bacterial products remains uncertain. We have discussed the standard working model of the initial phase of bacterial secretion [11], but observations in the present study led us to modify this model, as illustrated in Figure 4. Further careful and detailed studies are required to evaluate the validity of this model. 
Figure 3. HAADF-STEM images of OUMS1 and associated structures in Bi-stained cross sections prepared from a two-day-old culture and elemental maps by EDX area analysis. (a) Enlarged image of a bacterial cell with an immature sheath shown in inset. Note the highly electron-dense outer layer composed of intermingled fibrils (double star), suggesting a heavy deposition of aqueous-phase inorganic elements. The fibrils of the inner layer (single star) were much thicker than those in one-day-old culture (Figure 2(a)); (b) Bi map showing intense signals in the cell and the immature sheath; (c) Fe distribution map showing intense signals, particularly in fibrils of the outer sheath layers; (d) P distribution map showing intense signals, particularly in the sheath fibrils; (e) Si distribution map showing intense signals, particularly in the sheath fibrils. Scale bar $=100 \mathrm{~nm}$, except $500 \mathrm{~nm}$ in (a) inset. $\mathrm{BC}$, bacterial cell; $\mathrm{CE}$, cell envelope; IS, immature sheath; IVS, intervening space.
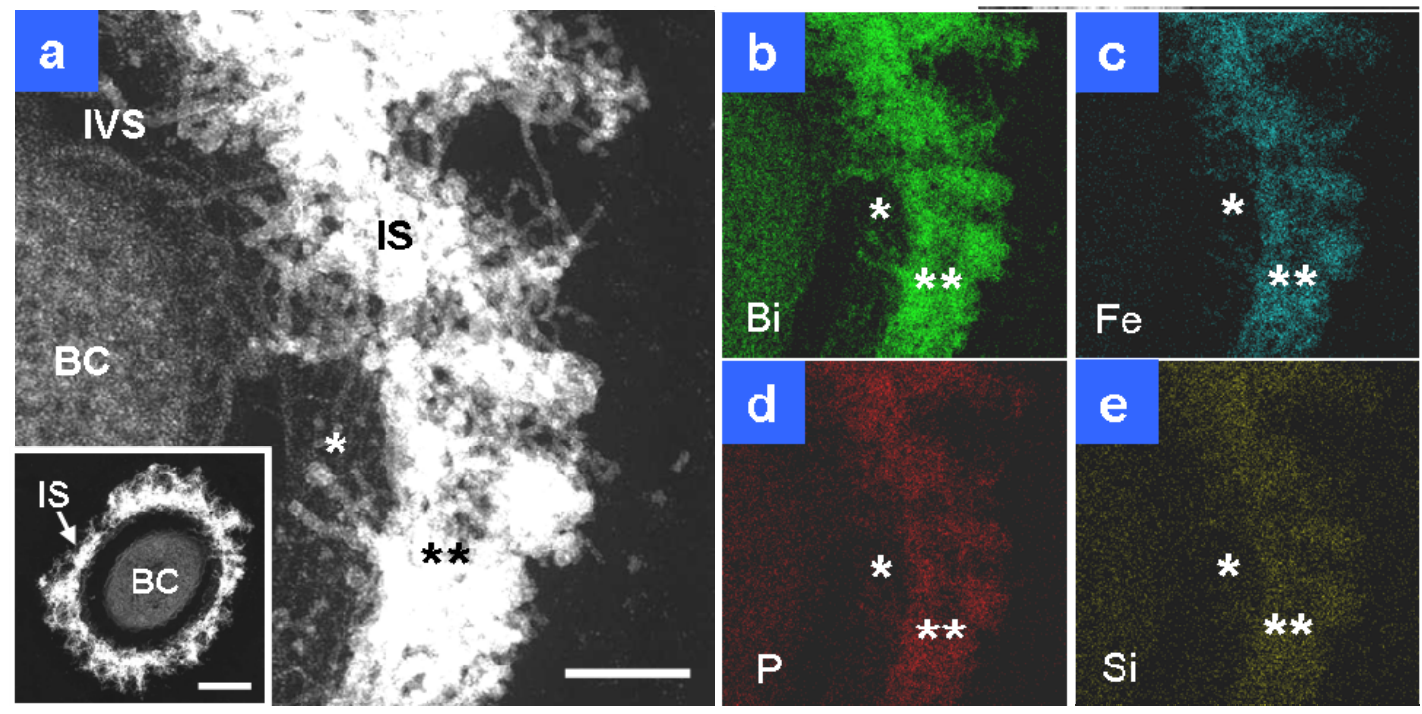

Figure 4. Working model of the initial phase of the assemblage of fibrils composed of bacterial secretions that form the immature sheath skeleton of cultured OUMS1. Bacterial secretion from the cell envelope may occur by (a) direct globular secretion; (b) direct thread secretion; and/or (c) indirect secretion via a pili-like mechanism. The secretion might be transported outwards to form the fibril assembly of the sheath skeleton, followed by aqueous-phase inorganic element deposition.

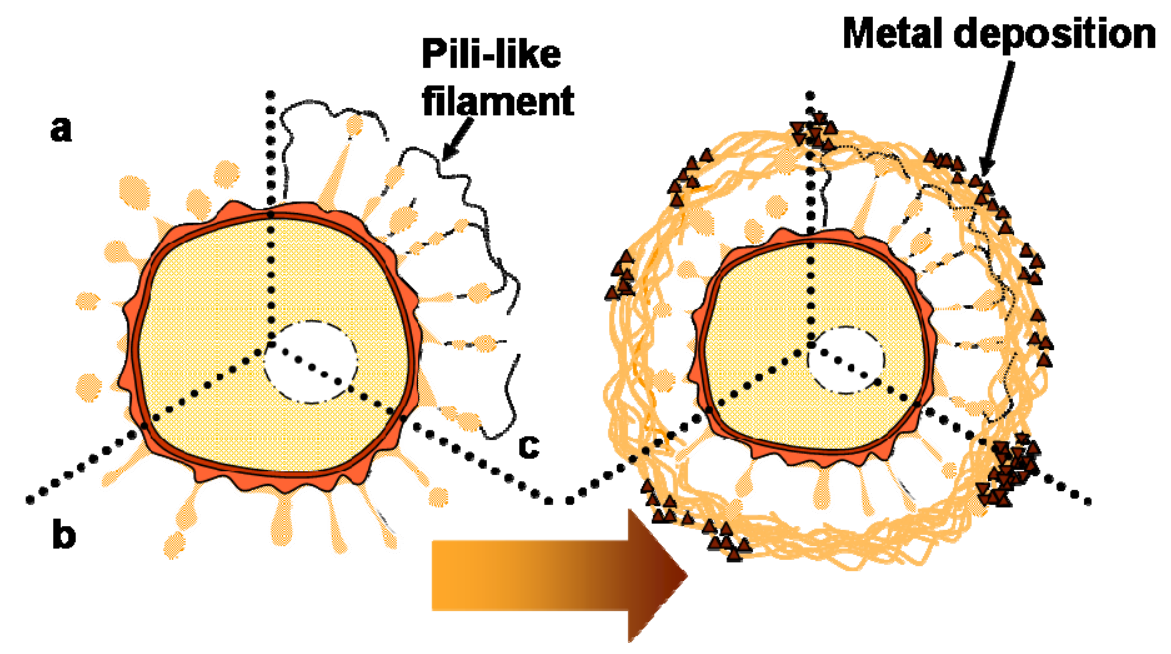


This study focused on the assemblage of bacterial saccharic polymers and the deposition of aqueous-phase inorganic elements during the formation of the immature sheath. Previous studies $[1,5,19,23]$ have reported that other chemical groups, such as free sulfhydryl and carboxyl groups, are associated with the $\mathrm{C}$ components and they could provide the sheath with numerous sites for the binding of metal cations, especially $\mathrm{Mn}^{2+}$ and $\mathrm{Fe}^{2+}$. The linkage of $\mathrm{C}$ elements in the sheath with other elements such as $\mathrm{P}, \mathrm{Si}$, and $\mathrm{Fe}$ and the chemical groups involved in the formation of the inorganic/organic hybrid complex remain attractive issues for future study. Understanding the initial phases of hybrid construction will provide insights into this remarkable bacterium-associated phenomenon. Such insights are a prerequisite for the design of any successful technology that might regulate bacterial growth and the character of this unique biogenic product.

\section{Experimental Section}

\subsection{Sample and Culturing}

Leptothrix sp. strain OUMS1 (NITE BP-860) (hereafter referred to as OUMS1) was isolated from flocculent ocherous deposits in the biological freshwater purification plant at Joyo City, Kyoto Prefecture, Japan and stored in a $-80{ }^{\circ} \mathrm{C}$ freezer [12]. By the method described by Sawayama et al. [12], OUMS1 was recovered from frozen storage and cultured in a silicon-iron-glucose-peptone (SIGP) liquid medium containing three Fe plates $\left(10 \times 10 \times 1.2 \mathrm{~mm}^{3}\right.$; 99.9\% purity; Kojundo Chem. Lab., Saitama, Japan) at $20^{\circ} \mathrm{C}$ on a rotary shaker at $70 \mathrm{rpm}$ on 1 or 2 days. Sheath-associated bacterial mats were gently scraped from the surface of the Fe plates and subjected to microscopic observation.

\subsection{Electron Microscopy}

Samples collected from Fe plate surfaces were fixed with a mixture of $2.5 \%$ glutaraldehyde, $1 \%$ $\mathrm{OsO}_{4}$, and $4.5 \%$ sucrose in $100 \mathrm{mM}$ cacodylate buffer ( $\mathrm{pH} 7.0$ ) on ice for $2 \mathrm{~h}$, before washing with ultrapure water and embedding them in $2 \%$ agar. Small pieces of the agar block were dehydrated with a graded series of ethanol and embedded in Quetol 651 resin mixture (Nisshin EM, Tokyo, Japan). Ultrathin sections were stained with uranyl acetate and lead solution (hereafter referred to as $\mathrm{U} / \mathrm{Pb}$-stained sections) and observed using TEM (H-7500, Hitachi, Tokyo, Japan) at an accelerating voltage of $80 \mathrm{kV}$.

To detect carbohydrates [24], ultrathin sections on copper grids were exposed to 40-fold-diluted alkaline Bi stock solution at $40{ }^{\circ} \mathrm{C}$ for $30 \mathrm{~min}$. The alkaline Bi stock solution contained $10 \%$ sodium hydroxide, $4 \%$ potassium sodium tartrate, and $2 \%$ bismuth subnitrate in ultrapure water. After repeated washings with ultrapure water, the grids were subjected to TEM observation (hereafter referred to as Bi-stained sections).

The $\mathrm{Bi}$ - and $\mathrm{U} / \mathrm{Pb}$-stained ultrathin sections on copper grids were first covered with a formvar film using a routine method before being coated with carbon to increase the tolerance of the specimen to an intense electron beam. HAADF and EDX detectors were attached to a transmission electron microscope (JEOL JEM-2100F, $200 \mathrm{kV}$ accelerating voltage) and used for HAADF-STEM imaging and elemental mapping of the bacterial cell and associated structures, respectively. Bright-field STEM images were also obtained for reference. 


\section{Conclusions}

The present study revealed the initial phase of sheath construction of Leptothrix sp. strain OUMS1 in culture condition. The first construction step was a globular and/or thread-like secretion on the surface of the bacterial cell envelope, followed by transportation of secreted bodies across the intervening space away from the cell to form an immature sheath skeleton comprising assembled and intermingled fibrils. The second step was prominent thickening of an inner skeleton layer of almost parallel aligned fibrils and heavy deposition of Fe along with significant deposition of $\mathrm{P}$ and $\mathrm{Si}$ in an outer intermingled fibrous layer. Secretion of saccharic polymers from the bacterial cell surface apparently acted as a trigger for construction of an immature sheath skeleton.

\section{Acknowledgments}

This study was financially supported by a Special Grant for Education and Research and a Grant-in-Aid for Research Activity Start-up (No. 22860040, 2010 and 2011) from the Ministry of Education, Culture, Sports, Science, and Technology, Japan (for J. T. and H. H., respectively), and a Grant-in-Aid from the Yakumo Foundation for Environmental Science (for H.H. and T. S.).

\section{References}

1. Spring, S. The genera Leptothrix and Sphaerotilus. Prokaryotes 2006, 5, 758-777.

2. Takeda, M.; Makita, H.; Ohno, K.; Nakahara, Y.; Koizumi, J. Structural analysis of the sheath of a sheathed bacterium, Leptothrix cholodnii. Int J. Biol. Macromol. 2005, 37, 92-98.

3. Van Veen, W.L.; Mulder, E.G.; Deinema, M.H. The Sphaerotilus-Leptothrix group of bacteria. Microbiol. Rev. 1978, 42, 329-356.

4. Emerson, D.; Ghiorse, W.C. Ultrastructure and chemical composition of the sheath of Leptothri. x discophora SP-6. J. Bacteriol. 1993, 175, 7808-7818.

5. Emerson, D.; Ghiorse, W.C. Role of disulfide bonds in maintaining the structural integrity of the sheath of Leptothrix discophora SP-6. J. Bacteriol. 1993, 175, 7819-7827.

6. Ghiorse, W.C. Biology of iron- and manganese-depositing bacteria. Annu. Rev. Microbiol. 1984, $38,515-550$.

7. Sakai, T.; Miyazaki, Y.; Murakami, A.; Sakamoto, N.; Ema, T.; Hashimoto, H.; Furutani, M.; Nakanishi, M.; Fujii, T.; Takada, J. Chemical modification of biogenous iron oxide to create an excellent enzyme scaffold. Org. Biomol. Chem. 2010, 8, 336-338.

8. Suzuki, T.; Hashimoto, H.; Matsumoto, N.; Furutani, M.; Kunoh, H.; Takada, J. Nanometer-scale visualization and structural analysis of the inorganic/organic hybrid structure of Gallionella ferruginea twisted stalks. Appl. Environ. Microbiol. 2011, 77, 2877-2881.

9. Suzuki, T.; Hashimoto, H.; Ishihara, H.; Kasai, T.; Kunoh, H.; Takada, J. Structural and spatial associations between $\mathrm{Fe}, \mathrm{O}$, and $\mathrm{C}$ in the network structure of the Leptothrix ochracea sheath surface. Appl. Environ. Microbiol. 2011, 77, 7873-7875.

10. Chan, C.S.; Stasio, G.D.; Welch, S.A.; Girasole, M.; Frazer, B.H.; Nesterova, M.V.; Fakra, S.; Branfield, J.F. Microbial polysaccharides template assembly of nanocrystal fibers. Science 2004, 303, 1656-1658. 
11. Furutani, M.; Suzuki, T.; Ishihara, H.; Hashimoto, H.; Kunoh, H.; Takada, J. Assemblage of bacterial saccharic microfibrils in sheath skeleton formed by cultured Leptothrix sp. strain OUMS1. J. Mar. Sci. Res. Dev. 2011, in press.

12. Sawayama, M.; Suzuki, T.; Hashimoto, H.; Kasai, T.; Furutani, M.; Miyata, N.; Kunoh, H.; Takada, J. Isolation of a Leptothrix strain, OUMS1, from ocherous deposits in groundwater. Curr. Microbiol. 2011, 63, 173-180.

13. Hashimoto, H.; Yokoyama, S.; Asaoka, H.; Kusano, Y.; Ikeda, Y.; Seno, M.; Takada, J.; Fujii, T.; Nakanishi, M.; Murakami, R. Characteristics of hollow microtubes consisting of amorphous iron oxide nanoparticles produced by iron oxidizing bacteria, Leptothrix ochracea. J. Magnetism Magnetic Mater. 2006, 310, 2405-2407.

14. Suzuki, T.; Hashimoto, H.; Itadani, A.; Matsumoto, N.; Kunoh, H.; Takada, J. Silicon and phosphorus linkage with iron via oxygen in amorphous matrix of Gallionella. Appl. Environ. Microbiol. 2011, in press.

15. Mandai, K.; Korenaga, T.; Ema, T.; Sakai, T.; Furutani, M.; Hashimoto, H.; Takada, J. Biogenous iron oxide-immobilized palladium catalyst for the solvent-free Suzuki-Miyaura coupling reaction. Tetrahedron Lett. 2011, 53, 329-332.

16. Ema, T.; Miyazaki, Y.; Kozuki, I.; Sakai, T.; Hashimoto, H.; Takada, J. Highly active immobilized on biogenous iron oxide via an organic bridging group: The dramatic effect of the immobilization support on enzymatic function. Green Chem. 2011, 13, 3187-3195.

17. Boonfueng, T.; Axe, L.; Yee, N.; Hahn, D.; Ndiba, P.K. Zn-sorption mechanisms onto sheathed Leptothrix discophora and the impact of the nanoparticulate biogenic Mn oxide coating. J. Colloid Interface Sci. 2009, 333, 439-447.

18. Templeton, A.S.; Trainor, T.P.; Traina, S.J.; Spormann, A.M.; Brown, G.E., Jr. Pb(II) distributions at biofilm-metal oxide interfaces. Proc. Natl. Acad. Sci. 2001, 98, 11897-11902.

19. Emerson, D.; Ghiorse, W.C. Isolation, cultural maintenance, and taxonomy of a sheath-forming strain of Leptothrix discophora and characterization of manganese-oxidizing activity associated with the sheath. Appl. Environ. Microbiol. 1992, 58, 4001-4010.

20. Koebnik, R. The role of bacterial pili in protein and DNA translocation. Trends in Microbiol. 2001, 9, 586-590.

21. O’Toole, G.; Kaplan, H.B.; Kolter, R. Biofilm formation as microbial development. Annu. Rev. Microbiol. 2000, 54, 49-79.

22. Proft, T.; Baker, N. Pili in Gram-negative and Gram-positive bacteria-structure, assembly and their role in disease. Cell. Mol. Life Sci. 2009, 66, 613-635.

23. Ghiorse, W.C.; Hirsch, P. An ultrastructural study of iron and manganese deposition associated with extracellular polymers of Pedomicrobium-like bacteria. Arch. Microbiol. 1979, 123, 213-226.

24. Park, P.; Ohno, T.; Kato-Kikuchi, H.; Miki, H. Alkaline bismuth stain as a tracer for Golgi vesicles of plant cells. Stain Technol. 1987, 62, 253-256.

(C) 2011 by the authors; licensee MDPI, Basel, Switzerland. This article is an open access article distributed under the terms and conditions of the Creative Commons Attribution license (http://creativecommons.org/licenses/by/3.0/). 